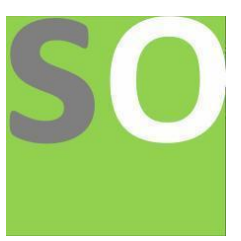

Article title: New Tuning Approach of Fuzzy Logic System Using Proportional Integral Observer for Tracking a Nonlinear System

Authors: Mustefa Jibril[1]

Affiliations: Dire Dawa University, Dire Dawa, Ethiopia[1]

Orcid ids: 0000-0002-3165-2410[1]

Contact e-mail: mustefazinet1981@gmail.com

License information: This work has been published open access under Creative Commons Attribution License http://creativecommons.org/licenses/by/4.0/, which permits unrestricted use, distribution, and reproduction in any medium, provided the original work is properly cited. Conditions, terms of use and publishing policy can be found at https://www.scienceopen.com/.

Preprint statement: This article is a preprint and has not been peer-reviewed, under consideration and submitted to ScienceOpen Preprints for open peer review.

DOI: 10.14293/S2199-1006.1.SOR-.PPDXLKS.v1

Preprint first posted online: 27 September 2021

Keywords: Proportional integral observer, Fuzzy proportional integral observer, Active suspension system 


\title{
New Tuning Approach of Fuzzy Logic System Using Proportional Integral Observer for Tracking a Nonlinear System
}

\author{
Mustefa Jibril \\ School of Electrical \& Computer Engineering, Dire Dawa Institute of Technology, Dire Dawa, \\ Ethiopia \\ mustefa.jibril@ddu.edu.et
}

\begin{abstract}
Proportional integral observer (PIO) for tracking a nonlinear method has a lower sentiency to cipher the state and output variables. So a more nonlinear controller has to be else to control to activity. In this paper, a fuzzy logic (FLC) controller has been added to the PIO to meliorate the calculation transmute. A fuzzy proportional integral observer (FPIO) for following a nonlinear system has been premeditated to decimate the susceptibleness to cipher the tell and turnout variables with the existent posit and product variables. The FPIO controller has been tested for improving the estimation control using a nonlinear quarter vehicle active suspension system with a nonlinear hydraulic actuator. A comparison simulation of the proposed nonlinear system for estimating the state variables and tracking the output (suspension deflection) with a set point bump road disturbance using FPIO and PIO. The comparison simulation result shows that the estimated state variables and system output match the actual ones perfectly using a fuzzy PIO controller.
\end{abstract}

Keywords: Proportional integral observer, Fuzzy proportional integral observer, Active suspension system

\section{Introduction}

In-state feedback compels systems, all denote state variables are requisite for feedback to set the system unchangeability. Proportionate integral observer (PIO) was foremost designed by S. Beale and B. Shafai to design observer-based controller formatting less sensitivity to the incessant fluctuation of the system by adding an integral law to the observer, which provides the extra extent of freedom [1].

The essential look of the FLC is that old to modify the interaction changing based on the entropy of the manipulator into correction front practical to the design under control. A standard mechanism much as PID individual is efficacious and offers a regnant technique to linear systems. In the debate of nonlinear systems classical supervisor does not yield copasetic value due to the nonlinearities of these methods [3]. Therefore, FLC may be an effectual stillness to moderate these nonlinear systems.

In this paper, a fuzzy proportional integral observer-based controller has been designed to eliminate the delicateness to parameter change of the system completely by using the tracking system method. This system is experimentation to prove the perfectness of the estimated state with the actual estate and the precision computations of the output variable.

\section{Material and Methods}

2.1 Proportional Integral Observer Control

The state-space method of an nth inflict, $p$ input and q output complex with 1 independent of invariable parameter reckon becomes as: 


$$
\left.\begin{array}{l}
\dot{x}=A x+B u+E d \\
d^{\cdot}=0
\end{array}\right\}
$$

The schemes state vector $\mathrm{x}$ is $\mathrm{n} \times 1$, the outline input vector $\mathrm{u}$ is $\mathrm{p} \times 1$, and the independent disturbance $d$ is an $1 \times 1$ vector. In the situation of the unwanted disturbance, mold is unknown, the matrix form $\mathrm{E}$ can be assumed to be an identity matrix with the same order of the system. The output $\mathrm{y}$, a $\mathrm{q} \times 1$ vector, of the design is:

$$
y=C x
$$

The proportional integral observer is constructed to approximation state variables using the system input and output. The state-space model of the proportional-integral observer becomes:

$$
\hat{x}=A \hat{x}+B u+L(y-C \hat{x})
$$

Where $\mathrm{x}^{\wedge}$ is the estimated state variables. Subtract Equation (3) from (1), letting e $=\mathrm{x}-\mathrm{x}^{\wedge}$, where the error between actual and estimated variables and disturbances, so that:

$$
\dot{e}=\dot{x}-\hat{x}=A x+E d-(A-L C) \hat{x}-L y=(A-L C) e+E d
$$

If there is no disturbance in intrigue $(\mathrm{d}=0)$, a proportional-integral observer has the ability to approximation the state variables, if (A-LC) is Routh-Hurwitz stable in which all eigenvalues of (A-LC) have negative actuality parts [4]. However, if $d$ is a non-zero constant, their testament is a constant steady-state error between the estimated and actual state variables.

To eliminate this error in estimation, disturbance observer (DO) is described as follows:

$$
\left.\begin{array}{l}
\dot{\hat{x}}=A \hat{x}+B u+L_{P}(y-C \hat{x})+E \dot{\hat{d}} \\
\dot{\hat{d}}=L_{I}(y-C \hat{x})
\end{array}\right\}
$$

The state-space model of the proportional-integral observer becomes:

$$
\left.\begin{array}{l}
\dot{\hat{x}}=A \hat{x}+B u+E v+G(y-C \hat{x}) \\
\dot{v}=F(y-C \hat{x})
\end{array}\right\}
$$

Comparison of equation (5) and equation (6) shows that it is obvious that disturbance bystanders can be regarded as a proportional-integral observer in a special case. The system block of proportional-integral observer for the tracing method is shown in Figure 1 below.

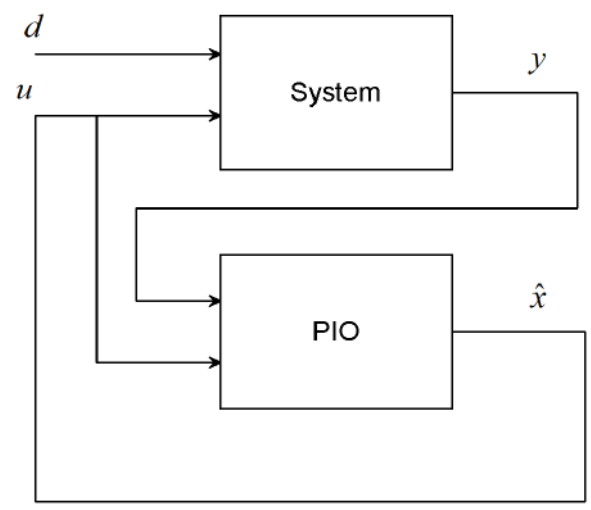

Figure 1. Block diagram of proportional-integral observer tracking system 
The state-space model of the system with the unwanted disturbance is shown in Equation (1). The two equations can be combined and defined as $z=\left[\begin{array}{l}x \\ d\end{array}\right]$, so that

$$
\dot{z}=\left[\begin{array}{ll}
A & E \\
0 & 0
\end{array}\right]\left[\begin{array}{l}
x \\
d
\end{array}\right]+\left[\begin{array}{l}
B \\
0
\end{array}\right] u=A_{z} z+B_{z} u
$$

The output of the system is given by the above equations yields:

$$
y=C x=\left[\begin{array}{ll}
C & 0
\end{array}\right]\left[\begin{array}{l}
x \\
d
\end{array}\right]=C_{Z} z
$$

The state-space model of the undesired disturbance observer given by equation (5) can also be rewritten into the above equations by defining $\hat{z}=\left[\begin{array}{l}\hat{x} \\ \hat{d}\end{array}\right]$ :

$$
\dot{\hat{z}}=\left[\begin{array}{ll}
A-L_{p} C & E \\
-L_{I} C & 0
\end{array}\right] \hat{z}+\left[\begin{array}{c}
L_{p} \\
L_{I}
\end{array}\right] y+\left[\begin{array}{l}
B \\
0
\end{array}\right] u
$$

This implies

$$
\begin{aligned}
A_{Z(n+l \times n+l)} & =\left[\begin{array}{ll}
A & E \\
0 & 0
\end{array}\right] \\
B_{Z(n+l \times p)} & =\left[\begin{array}{l}
B \\
0
\end{array}\right] \\
C_{Z(q \times n+l)} & =\left[\begin{array}{ll}
C & 0
\end{array}\right] \\
L_{Z(n+l \times q)} & =\left[\begin{array}{l}
L_{p} \\
L_{I}
\end{array}\right]
\end{aligned}
$$

Equation (9) becomes:

$$
\left.\begin{array}{rl}
\dot{\hat{z}} & =\left(\left[\begin{array}{cc}
A & E \\
0 & 0
\end{array}\right]-\left[\begin{array}{c}
L_{p} \\
L_{I}
\end{array}\right]\left[\begin{array}{ll}
C & 0
\end{array}\right]\right) \hat{z}+\left[\begin{array}{c}
L_{p} \\
L_{I}
\end{array}\right] y+\left[\begin{array}{l}
B \\
0
\end{array}\right] u \\
& =\left(A_{Z}-L_{Z} C_{Z}\right) \hat{z}+L_{Z} y+B_{Z} u
\end{array}\right\}
$$

Subtracting Equation (7) from Equation (10), letting $e=z-z$, which is the error between actual and estimated variables and the undesired disturbances, so that:

Noticing that $\mathrm{y}=\mathrm{Czz}$ in Equation (8), the equation above can be described as:

$$
\dot{e}_{z}=A_{Z} z-L_{Z} C_{Z} z-\left(A_{Z}-L_{Z} C_{Z}\right) \hat{z}=\left(A_{Z}-L_{Z} C_{Z}\right) e
$$


Whereas long as $A_{Z}-L_{Z} C_{Z}=\left[\begin{array}{cc}A-L_{p} C & E \\ -L_{I} C & 0\end{array}\right]$ is Routh-Hurwitz stable, the error between actual and estimated variables will become zero as $t \rightarrow \infty$

Recall Equation (8) and (10):

$$
\left.\begin{array}{l}
\dot{\hat{z}}=\left(A_{Z}-L_{Z} C_{Z}\right) \hat{z}+L_{Z} y+B_{Z} u \\
y=C_{Z} z
\end{array}\right\}
$$

Comparisons of the above equations with the state-space model of proportional-integral observer described by Equation (2) and (3):

$$
\left.\begin{array}{l}
\dot{\hat{x}}=(A-L C) \hat{x}+L y+B u \\
y=C x
\end{array}\right\}
$$

The proportional integral observer can be applied to onlooker gain L planning for the proportionalintegral observer with this extended onlooker model for tracking systems [5].

\subsection{Fuzzy Controller Design}

In closed-loop dominion systems, the classical controller has been replaced by the FLC. This quantity that the IF-THEN rules and fuzzy membership functions replace the mathematical rule to experiment the system [2]. For the fuzzy logic mechanism, the signal variables are error (e) and derivative of error (de/dt), and the output Sus_def (suspension deflection) (u). Gaussian membership functions are utilized for inputs variables and the output. An error has 9 membership functions as shown in Figure 2, the derivative of error has 9 membership functions as shown in Figure 3, and output has nine membership functions as shown in Figure 4 below.
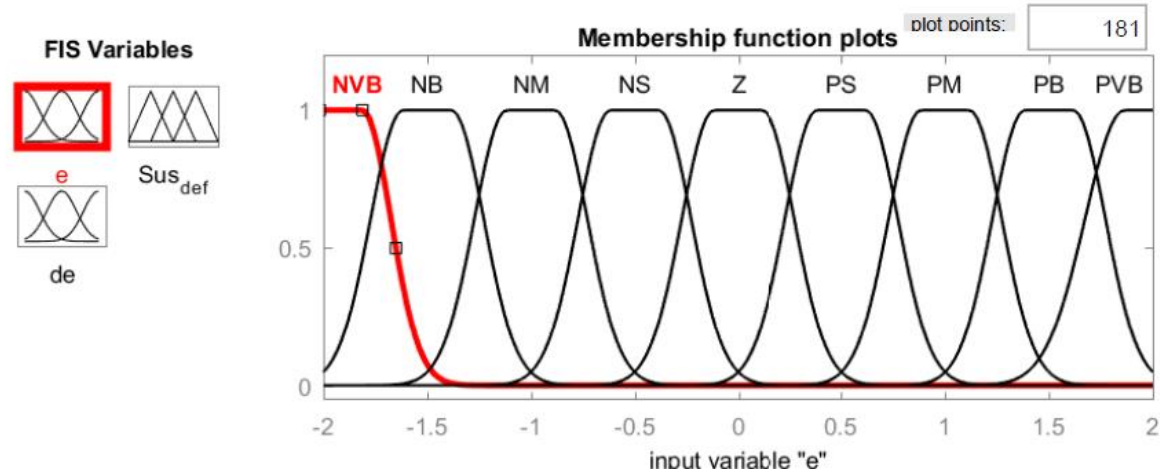

Figure 2 Error membership function

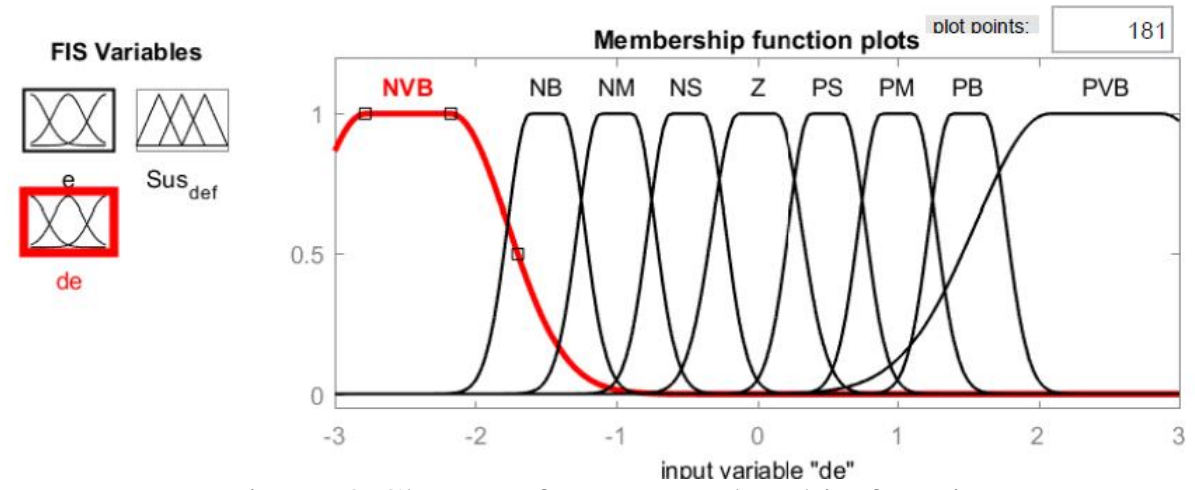

Figure 3 Change of error membership function 


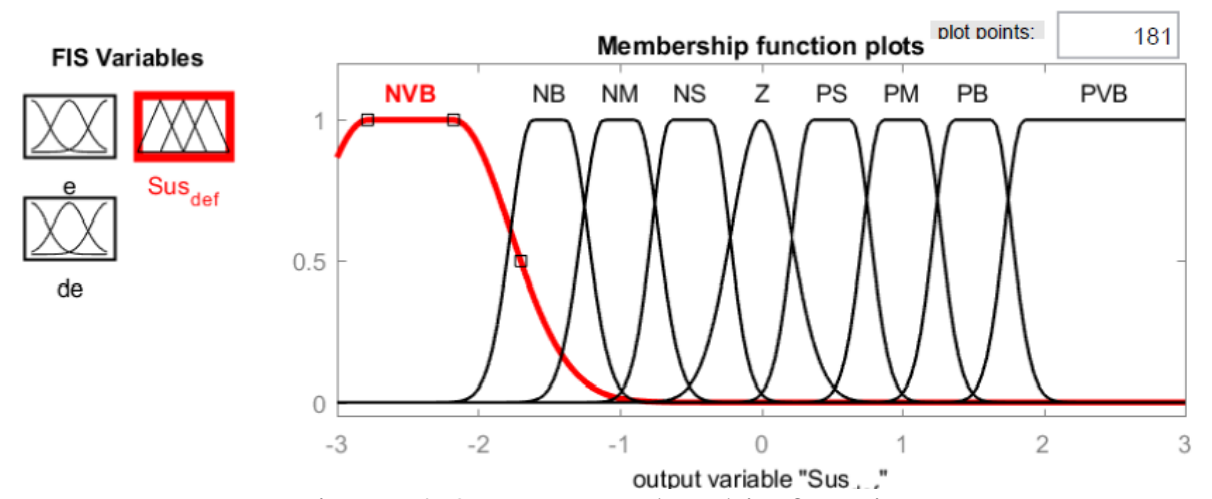

Figure 4 Output membership function

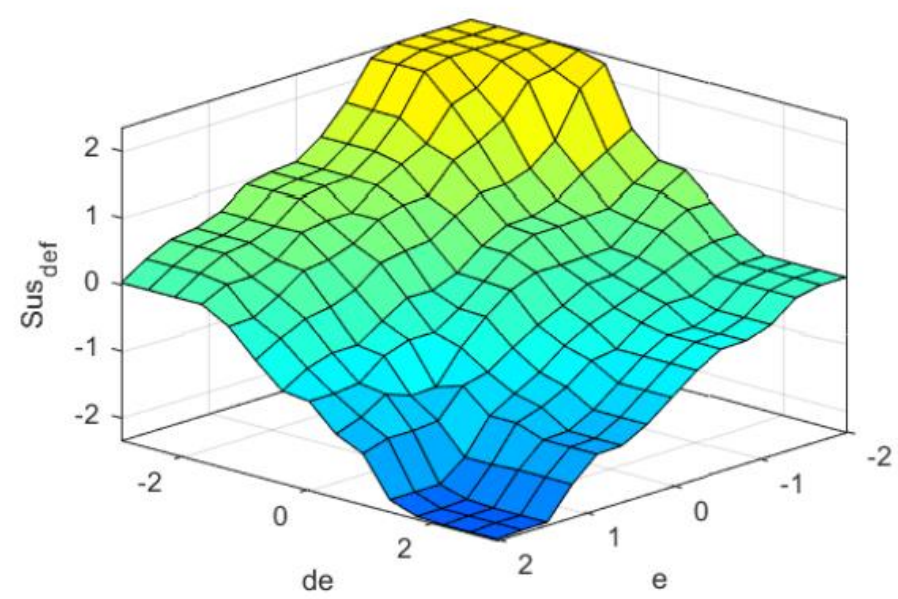

Figure 5 Surface membership function

The Mamdani-based fuzzy logic controller is selected for this paper as shown in Figure 6 below.

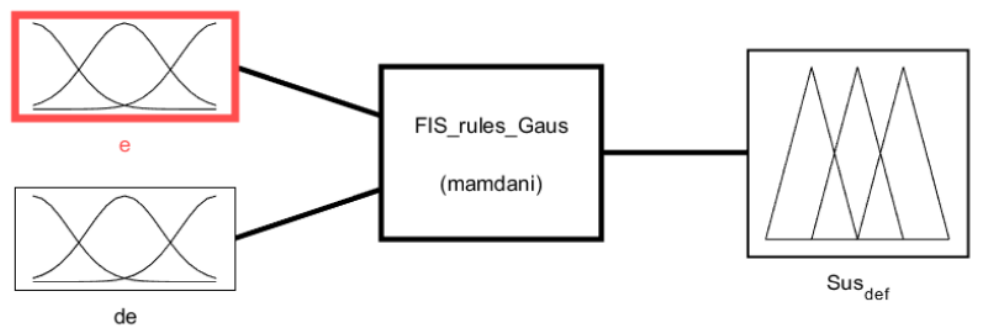

Figure 6 Mamdani based fuzzy logic controller

\subsubsection{Fuzzy Rule Base}

The fuzzy input variable e has nine membership functions and fuzzy input variable $\Delta \mathrm{e}$ has nine membership functions, and the output variable has nine membership functions. There are 81 rules generated as shown in Table 1.

Table 1 Fuzzy rule base 


\begin{tabular}{|c|c|c|c|c|c|c|c|c|c|c|}
\hline & \multirow[b]{2}{*}{ u } & \multicolumn{9}{|c|}{$\Delta \mathrm{e}$} \\
\hline & & $N V B$ & $N B$ & $N M$ & $N S$ & $Z$ & $P S$ & $P M$ & $P B$ & $P V B$ \\
\hline \multirow{9}{*}{ e } & $N V B$ & $P V B$ & PVB & $P V B$ & $P B$ & $P M$ & $P M$ & $P S$ & $Z$ & $Z$ \\
\hline & $N B$ & $P V B$ & $P V B$ & $P B$ & $P M$ & $P S$ & $P S$ & $P S$ & $Z$ & $Z$ \\
\hline & $N M$ & $P V B$ & $P B$ & $P M$ & $P S$ & $P S$ & $Z$ & $Z$ & $Z$ & $N S$ \\
\hline & $N S$ & $P B$ & $P M$ & $P M$ & $P S$ & $P S$ & $Z$ & $Z$ & $N S$ & $N S$ \\
\hline & $Z$ & $P M$ & $P M$ & $P S$ & $Z$ & $Z$ & $\bar{Z}$ & $N S$ & $N S$ & $N M$ \\
\hline & $P S$ & $P M$ & $P S$ & $P S$ & $Z$ & $N S$ & $N S$ & $N M$ & $N M$ & $N B$ \\
\hline & $P M$ & $P S$ & $P S$ & $Z$ & $N S$ & $N S$ & $N M$ & $N B$ & $N B$ & $N B$ \\
\hline & $P B$ & $P S$ & $Z$ & $Z$ & $N S$ & $N M$ & $N M$ & $N B$ & $N V B$ & $N V B$ \\
\hline & $P V B$ & $Z$ & $Z$ & $N S$ & $N M$ & $N M$ & $N B$ & $N B$ & $N V B$ & NVB \\
\hline
\end{tabular}

\section{The Proposed Controller Design}

To dominion the tracking system, a fuzzy logic supervisor has been added to the system to regulator the process using the difference between system output $y$ and reference input $r$. The block design of the fuzzy PIO schemes is shown in Figure 7 below.

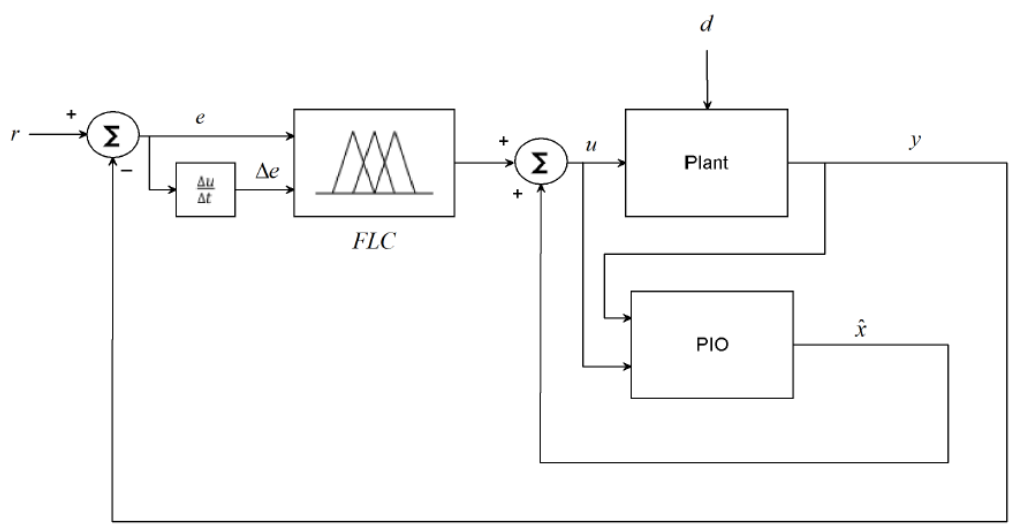

Figure 7 Block diagram of the plant with FPIO

\section{Result and Discussion}

The system with fuzzy PIO is designed in this section with nonlinear quarter vehicle active suspension with hydraulic actuator for state and output estimation by comparing the actual state with the estimated state with FPIO and PIO tracking systems.

\subsection{Case Study}

The nonlinear model description of the quarter vehicle active suspension system and the hydraulic actuator can be described as:

$$
\begin{aligned}
& M_{1} \ddot{x}_{1}=k_{1}^{l}\left(x_{2}-x_{1}\right)+k_{1}^{n l}\left(x_{2}-x_{1}\right)^{3}+B_{1}^{l}\left(\dot{x}_{2}-\dot{x}_{1}\right) \\
& -B_{1}^{m i x}\left|\dot{x}_{2}-\dot{x}_{1}\right|+B_{1}^{n l} \sqrt{\left|\dot{x}_{2}-\dot{x}_{1}\right| \operatorname{sgn}\left(\dot{x}_{2}-\dot{x}_{1}\right)}-F
\end{aligned}
$$




$$
\begin{aligned}
& M_{2} \ddot{x}_{2}=-k_{1}^{l}\left(x_{2}-x_{1}\right)-k_{1}^{n l}\left(x_{2}-x_{1}\right)^{3}+B_{1}^{l}\left(\dot{x}_{2}-\dot{x}_{1}\right)-B_{1}^{m i x}\left|\dot{x}_{2}-\dot{x}_{1}\right| \\
& -B_{1}^{n l} \sqrt{\left|\dot{x}_{2}-\dot{x}_{1}\right| \operatorname{sgn}\left(\dot{x}_{2}-\dot{x}_{1}\right)}+k_{2}^{n l}\left(x_{2}-\dot{z}\right)+B_{2}^{n l}\left(x_{2}-\dot{z}\right)+F
\end{aligned}
$$

Where

$M_{1}$ quarter body mass

$M_{2}$ quarter suspension mass

$x_{1}$ body travel displacement

$x_{2}$ suspension deflection displacement

$k_{1}^{l}$ Linear spring stiffness between mass 1 and mass 2

$k_{1}^{n l}$ nonlinear spring stiffness between mass 1 and mass 2

$k_{2}^{n l}$ nonlinear spring stiffness between mass 2 and road profile

$B_{1}^{l}$ Linear damping between mass 1 and mass 2

$B_{1}^{n l}$ nonlinear damping between mass 1 and mass 2

$B_{1}^{m i x}$ mixed damping effect between mass 1 and mass 2

$B_{2}^{n l}$ nonlinear damping between mass 2 and road profile

$Z$ road profile displacement

And

$$
Q=\operatorname{sgn}\left[P_{s}-\operatorname{sgn}\left(y_{d}\right) P_{0}\right] R_{d} \sqrt{\frac{1}{\rho}\left[P_{S}-\operatorname{sgn}\left(y_{d}\right) P_{0}\right]}
$$

Where

$Q$ is the hydraulic load drift

$R_{d}$ is the release coefficient, is the spool valve vicinity gradient

$P_{0}$ is the pressure inside the chamber of the hydraulic piston

$y_{d}$ is the valve displacement from its closed position

$\rho$ is the hydraulic fluid density

$P_{s}$ is the supply pressure

The parameters of the nonlinear quarter car active suspension and the hydraulic actuator are shown in Table 2 below.

Table 2 System parameters 


\begin{tabular}{|l|l|c|}
\hline Quarter body mass & $M_{1}$ & $600 \mathrm{Kg}$ \\
\hline Quarter suspension mass & $M_{2}$ & $130 \mathrm{Kg}$ \\
\hline Linear spring stiffness between mass 1 and mass 2 & $k_{1}^{l}$ & $1700 \mathrm{~N} / \mathrm{m}$ \\
\hline Nonlinear spring stiffness between mass 1 and mass 2 & $k_{1}^{n l}$ & $1850 \mathrm{~N} / \mathrm{m}$ \\
\hline Nonlinear spring stiffness between mass 2 and road profile & $k_{2}^{n l}$ & $19700 \mathrm{~N} / \mathrm{m}$ \\
\hline Linear damping between mass 1 and mass 2 & $B_{1}^{l}$ & $900 \mathrm{Ns} / \mathrm{m}$ \\
\hline Nonlinear damping between mass 1 and mass 2 & $B_{1}^{n l}$ & $980 \mathrm{Ns} / \mathrm{m}$ \\
\hline Mixed damping effect between mass 1 and mass 2 & $B_{1}^{\text {mix }}$ & $1280 \mathrm{Ns} / \mathrm{m}$ \\
\hline Nonlinear damping between mass 2 and road profile & $B_{2}^{n l}$ & $680 \mathrm{Ns} / \mathrm{m}$ \\
\hline Release coefficient of the spool valve vicinity gradient & $R_{d}$ & 0.4 \\
\hline Hydraulic fluid density & $\rho$ & $2900 \mathrm{Kg} / \mathrm{m}^{3}$ \\
\hline Supply pressure & $P_{s}$ & $6.8 \mathrm{Mpa}$ \\
\hline
\end{tabular}

\section{Tuning Method}

PIO is an algorithm that iteratively runs until it manages to get the minimum of a function. The PIO is used to moderate the membership function tuning for FLC. The objective function was from the predicted output compared to the input given. It is a simple mathematical method that is based on a differentiation equation where the initial point output was the move towards the targeted output by calculating the errors. Two (2) important parameters need to be considered which are the direction of movement and the size of the step that needs to be used. The direction of movement defines by the tangential of the initial point. The sharpness of the tangent line also shows how near the point to the minimum point and how to decide the learning rate that should be selected. Figure 8 shows the flow diagram of the FLC tuning algorithm. From Figure 8, the PIO will keep on running until the optimum condition is generated or the iteration reach.

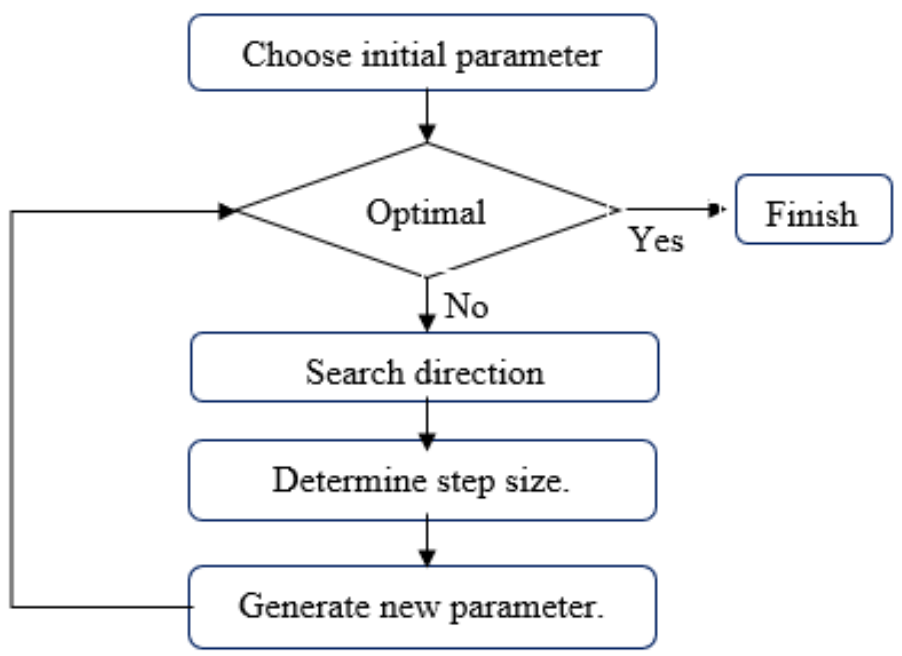

Figure 9: Flow diagram of FLC tuning algorithm 
The initial state of the system is $x_{o}=\left(\begin{array}{llll}0 & 0 & 0 & 0\end{array}\right)^{T}$. The PIO state-space representation is

$$
A_{P I O}=\left(\begin{array}{ccc}
-22.43 & 8 & 19.43 \\
-31.4 & -18 & 105.4 \\
-44.63 & 40 & 14.83
\end{array}\right), B_{P I O}=\left(\begin{array}{l}
27.13 \\
101.7 \\
38.43
\end{array}\right), C_{P I O}=\left(\begin{array}{lll}
1 & 0 & 0
\end{array}\right), D_{P I O}=0
$$

The Matlab/Simulink model of the quarter vehicle active suspension system with fuzzy PIO and PIO tracking systems is shown in Figure 9 below.

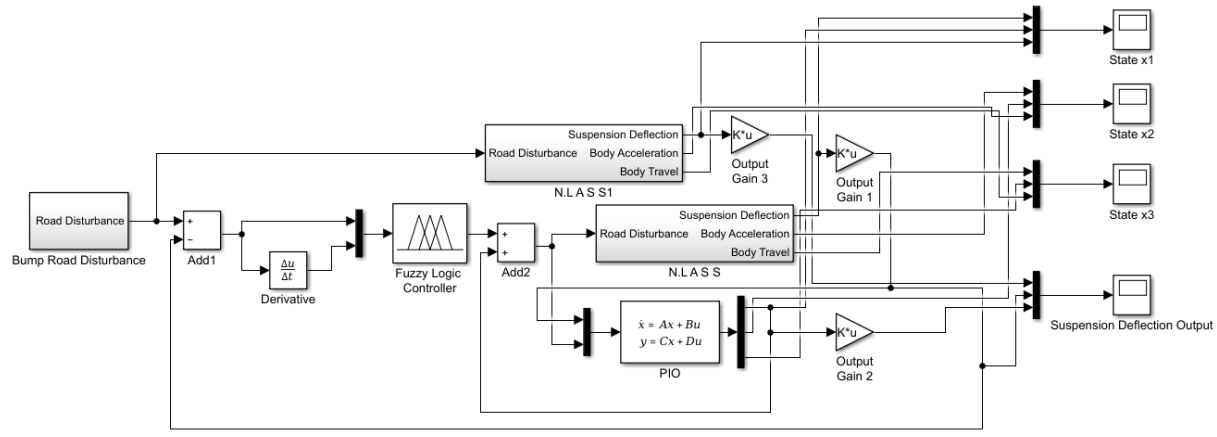

Figure 9 Simulink model of the proposed system

The output feedback gains $\mathrm{K} 1, \mathrm{~K} 2$, and $\mathrm{K} 3$ for tracking the system without observer are obtained by using pole placement and it becomes as:

$$
K_{1}=1.25, K_{2}=0.25, K_{3}=0.75
$$

The input for the system is a bump road disturbance of $10 \mathrm{~cm}$ as shown in Figure 10 below.

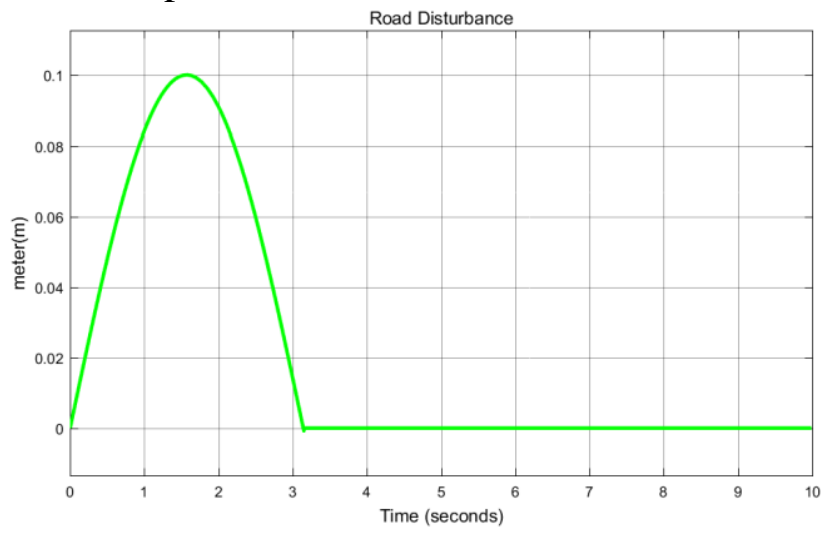

Figure 10 Road disturbance input

The simulation of the actual and estimated state variables $\mathrm{x} 1, \mathrm{x} 2, \mathrm{x} 3$, and the output variable $\mathrm{y}$ are shown in Figures 11, 12, 13, and 14 respectively. 


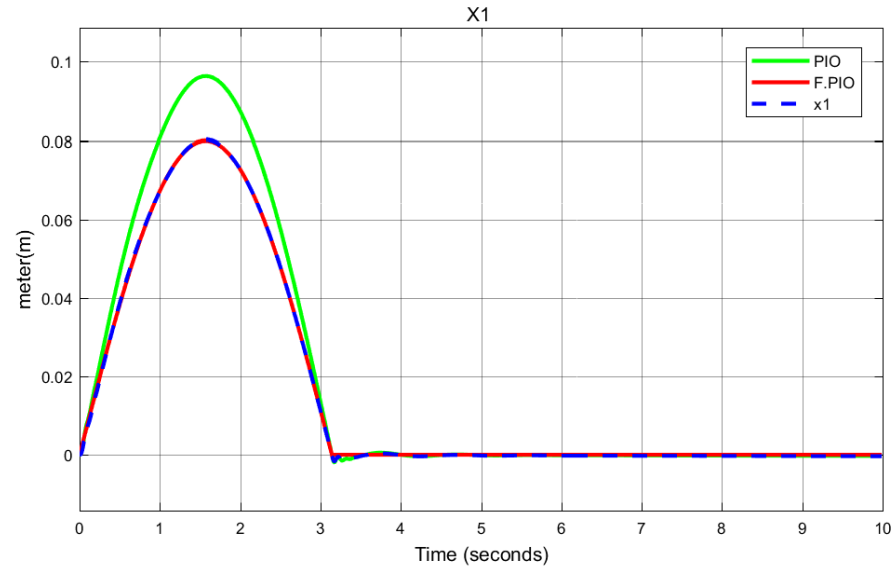

Figure 11 Estimated and actual state variable $\mathrm{x} 1$

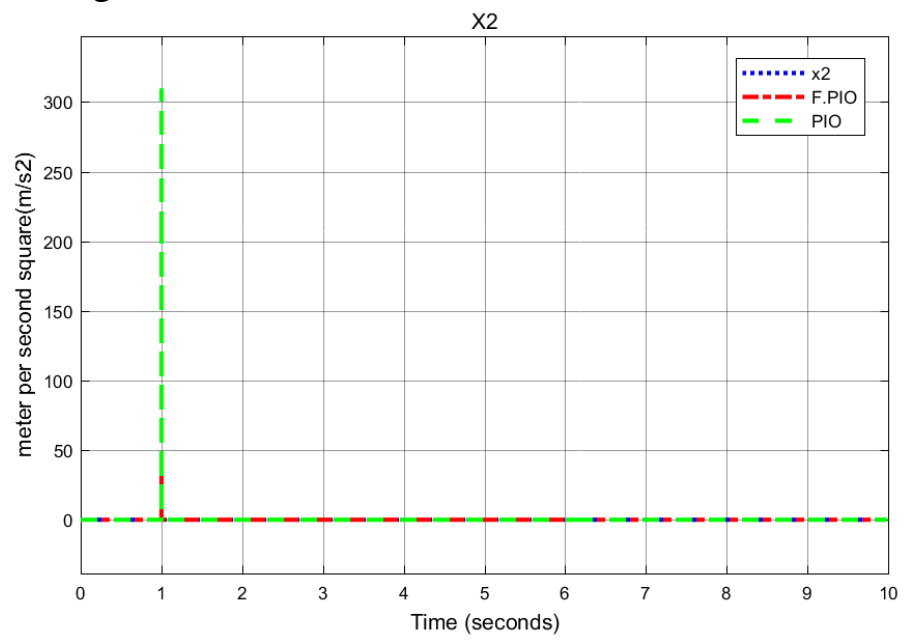

Figure 12 Estimated and actual state variable x2

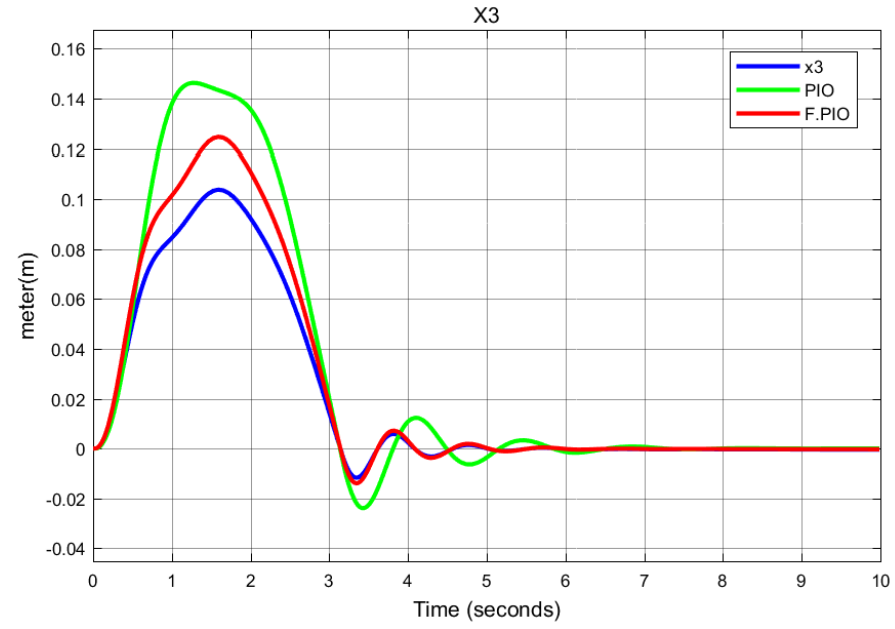

Figure 13 Estimated and actual state variable x3 


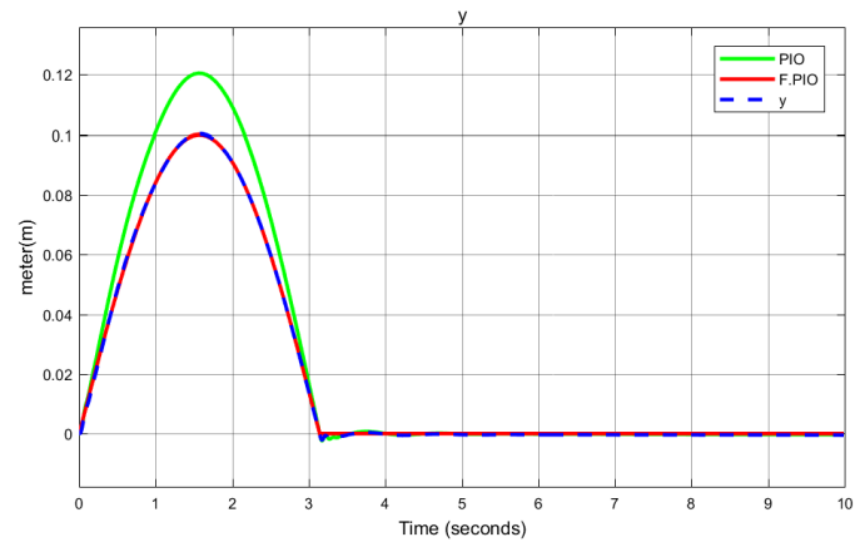

Figure 14 Estimated and actual system output y

From the above simulation result Figures, the estimated state variables $\mathrm{x} 1$ and $\mathrm{x} 2$ and the system output y exactly match the actual ones perfectly using FPIO tracking systems. The estimation of the state variable $\mathrm{x} 3$ (body travel) shows a small variation which is dependent on the nonlinear design of the quarter car active suspension system.

\section{Conclusion}

In this paper, a fuzzy proportional integral observer for tracing a nonlinear gadget has been designed to eliminate the sensitivity of estimating the state and output variables of the proposed system. The proposed controller has been tested with a nonlinear quarter vehicle active suspension system with a hydraulic actuator. Comparison of this system with FPIO and PIO controllers have been made for tracing a bump road disturbance. The estimated state and tracking of the design capability comparison results show that the system with FPIO estimated and actual state and design authority have exactly matched. In future work, this intrigue can be improved by modifying the fuzzy membership functions.

\section{Reference}

[1].Dong, Xiaonan, "Proportional Integral Observer (PIO) Design for Linear Control Systems" Open Access Master's Theses. Paper 955, http://digitalcommons.uri.edu/theses/955, 2016.

[2]. Alexander C. Abad, Dino Dominic Ligutan, Fuzzy Logic-Controlled 6-DOF Robotic Arm Color-based Sorter with Machine Vision Feedback, vol. 9, Manila: International Journal of Advanced Computer Science and Applications, Nov. 5, 2018.

[3].M. Namazov, "Fuzzy Logic Control Design for 2-Link Robot Manipulator in MATLAB/Simulink via Robotics Toolbox," IEEE, 2018.

[4].F. Bakhshande et al. "Proportional-Integral-Observer: A brief survey with special attention to the actual methods using ACC Benchmark" IFAC-PapersOnLine 48-1 (2015) 532-537

[5]. Baishun Liu et al. "Conventional and Added-Order Proportional Nonlinear Integral Observers" International Journal of Modern Nonlinear Theory and Application, 2014, 3, 210-220, Published Online December 2014 in SciRes. http://www.scirp.org/journal/ijmnta, http://dx.doi.org/10.4236/ijmnta.2014.35023.

[6]. Mustefa Jibril Taha, F. B. Kibret, V. Ramayya, and B. A. Zeru, "Design and evaluation of solar parabolic trough collector system integrated with conventional oil boiler," Arch. Electr. Eng., vol. 70, no. No 3, pp. 657-673, 2021, doi: 10.24425/aee.2021.137580. 
[7].Vihangkumar V. Naik et al. "Design and Implementation of Proportional Integral Observer-based Linear Model Predictive Controller" ACEEE Int. J. on Control System and Instrumentation, Vol. 4, No. 1, Feb 2013.

[8].T. BIAŁOŃ et al. "Parameter selection of an adaptive PI state observer for an induction motor" Bulletin of The Polish Academy of Sciences Technical Sciences, Vol. 61, No. 3, 2013 DOI: $10.2478 /$ bpasts-2013-0062

[9].Damien Koenig et al. "Design of Proportional-Integral Observer for Unknown Input Descriptor Systems" IEEE Transactions on Automatic Control, Vol. 47, No. 12, December 2002. 